\title{
MAIO DE 2019 NO BRASIL: uma luta por reconhecimento diante da desconstrução do valor social da universidade
}

\section{MAY 2019 IN BRAZIL: a struggle for recognition in the face of the} deconstruction of the social value of the university

Fernanda Cavicchia *

\section{Resumo}

Este trabalho analisa as manifestações de rua ocorridas no Brasil em maio de 2019 a partir da teoria de luta por reconhecimento, de Axel Honneth, a fim de apontar os elementos morais que motivaram os atos de protesto. Buscou-se mostrar que os discursos e ações do governo do presidente Jair Bolsonaro, de desprezo pelo meio acadêmico e científico, fizeram surgir na população universitária brasileira um sentimento de desrespeito, impulsionando a luta em defesa do valor social em desconstrução. Como procedimentos metodológicos, fez-se um resgate dos discursos e das ações do governo Bolsonaro para elencar as investidas contra a educação e o meio universitário e, posteriormente, analisouse a linguagem utilizada pelos manifestantes durante os protestos de 15 e 30 de maio. De posse do material coletado e posteriores interpretações, identificou-se que, das três etapas de reconhecimento definidas na teoria (amor, direito e solidariedade), o movimento de desvalorização social do meio acadêmico posto em prática pelo governo acontece na esfera da solidariedade, com potencial de deslocamento para o âmbito jurídico. Buscouse nas declarações do governo Bolsonaro as ofensas e degradações dirigidas à universidade, assim como foi examinada a linguagem dos protestos, visando indicar as expressões de uma reafirmação da identidade individual em resposta ao reconhecimento ameaçado.

Palavras-chave: Protestos; Juventude Universitária; Reconhecimento; Direitos.

\begin{abstract}
This work analyzes the street demonstrations that took place in Brazil in May 2019 with reference to Axel Honneth's theory of struggle for recognition, in order to highlight the moral elements that motivated the protests. It aims to show that the speeches and actions of the government of President Jair Bolsonaro, that revealed contempt for the academic and scientific sphere, generated a sentiment of disrespect in the Brazilian university population, motivating the struggle to defend the social value under deconstruction. As a methodological procedure, a list of the speeches and actions of the Bolsonaro government's attacks against education and the university environment was made and, subsequently, the language used by the protesters during the May 15 and 30 protests was analyzed. With the collected material and subsequent interpretations, the three patterns of
\end{abstract}

\footnotetext{
* Mestranda em ciências sociais pela Universidade Estadual Paulista "Júlio de Mesquita Filho" (UNESPFCLAr)/Brasil. E-mail: fscavicchia@gmail.com.
} 
recognition defined in the theory were identified (love, rights and esteem), the action of social devaluation of the academic sphere put into practice by the government occurs in the sphere of social esteem, with potential for displacement to the legal sphere. It is aimed to show in an analysis of Bolsonaro government's statements the offenses and degradations directed at the university, as well as examining the language of the protests, which indicate a reaffirmation of personal identity in response to threatened recognition.

Keywords: Protests; University Youth; Recognition; Rights.

\section{Introdução}

Em sua teoria de luta por reconhecimento, Honneth apresenta três esferas de reconhecimento (amor, direito e solidariedade) como etapas de um processo de formação da identidade individual e coletiva, e defende que os conflitos sociais, que surgem pela frustração de expectativas de reconhecimento, impulsionam o desenvolvimento moral das sociedades.

É a partir da teoria de Honneth que refletimos sobre os aspectos morais que motivaram os protestos contra o governo Jair Bolsonaro (sem partido; presidente do Brasil eleito para o mandato 2019-2022), ocorridos em maio de 2019 no Brasil após o então ministro da Educação, Abraham Weintraub, anunciar o corte de verbas das universidades federais. Em 15 de maio de 2019, milhares de pessoas foram às ruas em cerca de 200 cidades em todo o Brasil. ${ }^{1}$ Em 30 de maio, novos protestos tomaram as ruas do país.

O presente trabalho visa reconstruir a lógica dessas manifestações, identificando como elemento moral motivador dos atos o desrespeito experienciado pela população acadêmica. Esse sentimento é decorrente das ofensas dirigidas pelo governo à universidade pública, à ciência, à pesquisa, aos professores e aos estudantes. $^{2}$

Primeiramente, trazemos uma exposição sobre a teoria de luta por reconhecimento (HONNETH, 2009a). Em seguida, utilizamos os fundamentos da teoria

\footnotetext{
${ }^{1}$ Em pelo menos 170 cidades, segundo a Folha de S. Paulo (ATOS, 2019); em pelo menos 241 cidades, de acordo com o Estado de S. Paulo (GOVERNO, 2019); e em mais de 200 cidades, conforme o jornal O Globo (MAIS, 2019).

2 Embora as manifestações tenham sido protagonizadas por vários sujeitos, como mostraremos mais adiante, este estudo trata especificamente dos estudantes universitários.
} 
para identificar a dimensão moral das manifestações de maio de 2019, buscando mostrar que os atos de protesto são uma luta por estima social, ou seja, contra o movimento de desvalorização social da universidade pública. Nesse sentido, fazemos um resgate dos discursos e das ações do governo Bolsonaro, a fim de elencar as investidas contra a educação e o meio universitário, e analisamos a linguagem utilizada pelos manifestantes durante os protestos de 15 e 30 de maio. Por fim, mostramos como, nesse mesmo âmbito moral, a busca por reconhecimento também permeia a esfera do direito, traduzindo-se em uma defesa da igualdade de acesso à educação superior.

Com esses passos, visamos demonstrar que, por trás das manifestações, há uma motivação moral, que tem origem na experiência do desrespeito social. ${ }^{3}$

\section{Exposição teórica}

O filósofo Axel Honneth (1949-) faz parte de tradição de pensamento que ficou conhecida como Teoria Crítica. A expressão “Teoria Crítica” foi utilizada pela primeira vez por Max Horkheimer (1895-1973) em seu artigo Teoria tradicional e teoria crítica, publicado em 1937 na Revista de Pesquisa Social (Zeitschrift für Sozialforschung) do Instituto de Pesquisa Social vinculado à Universidade de Frankfurt, na cidade de Frankfurt am Main, na Alemanha. O Instituto foi fundado em 1924 por Horkheimer, Felix Weil (1898-1975) e Friedrich Pollock (1894-1970) e tinha como objetivo principal promover, em âmbito universitário, investigações científicas a partir da obra de Karl Marx (1818-1883) (NOBRE, 2011, p. 83-87).

Em 1983, Honneth defendeu sua tese de doutorado na Universidade Livre de Berlim, publicada em 1985 com o título Crítica do poder. Estágios de reflexão de uma teoria social crítica, apresentando o que denominou de "déficit sociológico" da Teoria Crítica, que seria a incapacidade dos autores dessa tradição intelectual de vincular a filosofia social à uma análise da sociedade fundamentada empiricamente. Segundo ele, autores como Horkheimer, Theodor W. Adorno (1903-1969) e Jürgen Habermas (1929-) não foram capazes de compreender o papel essencial dos conflitos sociais, que guardam

\footnotetext{
${ }^{3}$ Este artigo é a parte inicial de um trabalho que está em desenvolvimento como parte da pesquisa de mestrado junto ao Programa de Pós-Graduação em Ciências Sociais da UNESP-FCLAr.
} 
o potencial emancipatório, ou seja, que possuem os impulsos socias com capacidade para superar a própria realidade, vencendo as formas de dominação.

Em sua tese de livre-docência, apresentada em 1990 no Instituto de Filosofia da Universidade de Frankfurt, denominada Luta por reconhecimento. A gramática moral dos conflitos sociais, publicada em livro em $1992^{4}$, Honneth busca superar as falhas que ele havia apontado em Crítica do poder, desenvolvendo uma teoria que coloca o conflito moral como motor da reprodução social. Segundo ele, as mudanças sociais ocorrem a partir de um processo conflituoso de luta por reconhecimento e, para defender essa tese, ele retomou o modelo conceitual do jovem Hegel (1770-1831), que definiu como um "programa esplêndido" (HONNETH, 2009a, p. 113), e utilizou a psicologia social de George H. Mead (1863-1931) para promover uma atualização teórica sob as condições de um pensamento pós-metafísico.

Os escritos do jovem Hegel do período de Jena (1801-1806) introduziram uma mudança teórica no conceito hobbesiano de luta social, substituindo a ideia de sujeito atomístico pelo vínculo social entre os sujeitos, atribuindo uma motivação moral (busca por reconhecimento) aos conflitos entre indivíduos, e não os instintos de autoconservação. A própria individualização, segundo Hegel, ocorre a partir das relações sociais, e esse processo de socialização se dá por uma luta em que o sujeito busca, no outro, o reconhecimento de si mesmo.

Baseando-se em Hegel e Mead, Honneth (2009a) apresenta uma teoria com três esferas de reconhecimento: amor, direito e solidariedade. A cada etapa, o indivíduo conquista um estágio da sua autorrealização: pelo amor, desenvolve a autoconfiança; pelo direito, alcança o autorrespeito; e pela solidariedade, desenvolve a autoestima. A formação da identidade individual ocorre quando há o reconhecimento intersubjetivo. Quando esse reconhecimento é negado, quando há uma ruptura na relação de reconhecimento, surgem as lutas sociais.

O desrespeito experienciado pelo sujeito o conduz à ação política, em uma tentativa de reduzir o sofrimento causado pela frustração de suas expectativas. As formas

\footnotetext{
4 Neste trabalho, tomamos como referência a segunda edição da tradução em português dessa obra, publicada em 2009.
} 
de desrespeito referentes ao amor são maus-tratos e violação; ao direito, privação de direitos e exclusão social; à solidariedade, ofensas e degradação.

\section{Os protestos de maio e a dimensão moral}

Em 15 e 30 de maio de 2019, milhares de pessoas foram às ruas em diversas cidades brasileiras em defesa da educação e contra o corte de recursos das universidades federais. Os atos ocorreram após declarações do governo Bolsonaro direcionadas à comunidade universitária, as quais serão expostas mais adiante neste estudo, mas, a título de situar os acontecimentos, mencionamos a afirmação do ministro Weintraub que pode ser considerada o estopim das manifestações: "Universidades que, em vez de procurar melhorar o desempenho acadêmico, estiverem fazendo balbúrdia, terão verbas reduzidas" (AGOSTINI, 2019).

Segundo reportagem da Folha de S. Paulo (MANIFESTANTES, 2019), participaram dos atos de 15 de maio "manifestantes convocados por sindicatos contrários à reforma da Previdência, pauta original dos atos", além de "estudantes e professores de escolas e universidades públicas e privadas". Também havia, segundo o jornal, "militantes de partidos de esquerda", "integrantes de centrais de trabalhadores" e "milhares de manifestantes, crianças e idosos" sem ligação com siglas, em uma “participação espontânea”. O Estado de S. Paulo (PROTESTOS, 2019), ao descrever o ato de 15 de maio na capital paulista, considerado pelo jornal como o mais expressivo, afirmou que os "participantes carregavam bandeiras de movimentos estudantis, centrais sindicais e partidos de esquerda. Mas a grande maioria era formada por professores e pais de alunos que foram à manifestação de forma espontânea”. O jornal O Globo (PELA EDUCAÇÃO, 2019) informou que "professores e servidores do ensino público federal foram os catalizadores do movimento" de 15 de maio, que contou também com "alunos, pais e profissionais do ensino privado, além de trabalhadores de outras áreas, em menor número, e partidos políticos".

Nas exposições feitas pelos principais jornais do país, com circulação nacional e diária, as quais recorremos no intuito de descrever os atos, é possível perceber que as manifestações contaram com diversos sujeitos, mas que a comunidade universitária 
ocupou papel de destaque, seja por sua participação expressiva, seja por canalizar a principal pauta objetivada pelos atos: a defesa da educação. É nesse sentido que estabelecemos como objeto de análise deste trabalho os protestos de maio como uma forma de expressão da comunidade ligada à educação pública universitária, mais especificamente dos estudantes universitários. Enxergamos a amplitude dos protestos, que reuniram diversos atores, assim como entendemos que a retórica do governo assume uma dimensão ampla ao voltar-se para a educação e ao conhecimento científico em geral, e não apenas para as universidades públicas; no entanto, para este estudo, direcionamos a análise aos estudantes universitários, buscando entender como eles foram afetados pelo que chamamos de movimento de desprezo pela universidade.

Embora os jornais tenham destacado em suas reportagens a participação espontânea da população nos protestos de 15 de maio, os editoriais dos mesmos veículos, publicados em 17 de maio de 2019, descreveram as manifestações como uma demonstração da polarização política existente no Brasil, chamando a atenção para a perspectiva de um confronto político-partidário.

A Folha de S. Paulo, em uma crítica ao governo Bolsonaro por representar uma "ameaça à educação" com suas "intenções persecutórias", afirmou que o debate sobre o financiamento do ensino superior público foi transformado em um "confronto de bandeiras ideológicas" e abordou também o "oportunismo de forças oposicionistas" (IDIOTA, 2019). O jornal O Globo condenou o "perigoso estilo de governar pelo confronto", com ataques de "fundo ideológico à universidade", e destacou que as atitudes do governo fizeram "ressuscitar a oposição" (NÃO SE GOVERNA, 2019). O Estado de S. Paulo condenou a "hostilidade como método" de governo, e disse que temas cruciais para o país são desvirtuados pelo "alarido dos radicais" em um ambiente de "nós contra eles" (HOSTILIDADE, 2019).

Com o intuito de identificar e analisar a motivação moral dos estudantes universitários participantes das manifestações de maio de 2019 a partir da teoria de Honneth, buscamos apontar que, para além da disputa entre interesses políticos, esses protestos guardam a dimensão de uma luta por reconhecimento. Nosso objetivo é mostrar que nas ações coletivas ocorridas em maio de 2019 se encontra um sentimento de desrespeito, experienciado em decorrência de um movimento de desvalorização social da 
universidade pública, presente nas atitudes e discursos do governo Bolsonaro, conforme mostraremos mais adiante.

Das três formas de reconhecimento que se dão pelo amor, direito e estima social (solidariedade), o que aqui é definido como um movimento de desvalorização da comunidade acadêmica se encontra na terceira esfera. A estima social diz respeito a uma “comunidade de valores" (HONNETH, 2009a, p. 187) na qual existe uma aceitação recíproca das qualidades e capacidades particulares dos sujeitos. Nessa forma de reconhecimento, está inscrita uma dimensão histórica, ou seja, a estima social se altera de acordo com as modificações e evolução histórica da sociedade. Enquanto em comunidades tradicionais a estima social se dava pela honra, pela reputação social que a pessoa podia adquirir no seu estamento, nas comunidades modernas a estima está ligada a um pluralismo de valores, que pressupõe um maior número de relações simétricas constituídas pela diversidade de valores.

$\mathrm{Na}$ esfera da estima social, portanto, "o sujeito recebe a chance de experienciar [...] a si mesmo, em suas próprias realizações e capacidades [no estilo de vida escolhido], como valioso para a sociedade" (HONNETH, 2009a, p. 211). A desvalorização dos estudantes universitários, pesquisadores e professores pode ser vista como uma forma de reconhecimento recusado, como um movimento que visa retirar o valor social de determinados modos de vida constituintes da população universitária. O desrespeito referente a essa esfera de reconhecimento se expressa por ofensas e degradação.

Para exemplificar o que aqui definimos como um movimento de desvalorização da comunidade acadêmica, identificado pela vivência de um desrespeito na forma de degradação e ofensas, recorremos à narrativa estabelecida pelo governo Bolsonaro, constituída ainda como um discurso eleitoral e intensificada após as eleições de 2018, ampliando sua visibilidade e assumindo um caráter institucional. Seguem algumas declarações:

a) Jair Bolsonaro em entrevista à Globonews, em 18 de agosto de 2018: "Há uma certa tara por parte da garotada em ter um diploma. [...] essa tara por diploma superior não pode existir. É bom? Sim, vamos ter nossos mestres, nossos 
doutores, sim. Mas se você no ensino médio colocar algo técnico, você melhora nossa economia" (BOLSONARO DIZ, 2018).

b) Jair Bolsonaro em sua conta no Twitter, em 31 de dezembro de 2018: "Uma das metas para tirarmos o Brasil das piores posições nos rankings de educação do mundo é combater o lixo marxista que se instalou nas instituições de ensino. Junto com o Ministro de Educação e outros envolvidos vamos evoluir em formar cidadãos e não mais militantes políticos" (BOLSONARO, 2018).

c) Jair Bolsonaro em discurso durante a posse do novo ministro da educação, Abraham Weintraub, em 9 de abril de 2019: “Queremos uma garotada que comece a não se interessar por política, como é atualmente dentro das escolas, mas comece a aprender coisas que possam levar, quem sabe, ao espaço no futuro" (LINDNER, 2019).

d) Jair Bolsonaro em sua conta no Twitter, em 26 de abril de 2019: "O Ministro da Educação@abrahamWeinT [menção no Twitter a Abraham Weintraub] estuda descentralizar investimento em faculdades de filosofia e sociologia (humanas). Alunos já matriculados não serão afetados. O objetivo é focar em áreas que gerem retorno imediato ao contribuinte, como: veterinária, engenharia e medicina" (LOPES, 2019).

e) Abraham Weintraub em entrevista ao jornal O Estado de S. Paulo, em 29 de abril de 2019: "Universidades que, em vez de procurar melhorar o desempenho acadêmico, estiverem fazendo balbúrdia, terão verbas reduzidas" (AGOSTINI, 2019).

f) Jair Bolsonaro em entrevista à Rede TV, veiculada em 7 de maio de 2019: "Ninguém vai cortar dinheiro por prazer. Para algumas universidades, que formam militantes apenas, talvez o corte seja um pouquinho maior" (GUIMARÃES, 2019).

g) Jair Bolsonaro em entrevista à imprensa após as manifestações de rua, em 15 de maio de 2019: "É natural, é natural, mas a maioria ali é militante. Se você perguntar a fórmula da água, não sabe, não sabe nada. São uns idiotas úteis, uns imbecis que estão sendo usados de massa de manobra de uma minoria 
espertalhona que compõe o núcleo das universidades federais no Brasil" (BATISTA; ORTE, 2019).

h) Waldir Soares de Oliveira, líder do PSL ${ }^{5}$ na Câmara Federal, em 15 de maio de 2019: “O que acontece é que as pessoas não estão acostumadas com as palavras firmes e duras do presidente. As pessoas são manipuladas, é uma minoria. Quantas pessoas foram para rua? Quem foi? Foram aqueles fumadores de maconha, aqueles baderneiros" (TRUFFI; RIBEIRO, 2019).

Com esses exemplos, damos corpo ao que denominamos movimento de desvalorização social, de desprezo ou de degradação da universidade. De acordo com nossa fundamentação teórica, as relações de reconhecimentos frustradas ou fracassadas são aquelas que se expressam na forma de um desrespeito. $\mathrm{O}$ desrespeito referente à esfera da estima social é caracterizado na forma de ofensas e degradação. Por isso, palavras presentes nos exemplos anteriores, como "tara", "lixo marxista", "militantes políticos", "balbúrdia", "idiotas", "imbecis" e "fumadores de maconha", podem ser classificadas como ofensas e, portanto, como um desrespeito, pois depreciam a figura do estudante/pesquisador ou de professores universitários, assim como agridem e desprezam a produção científica.

Para entendermos como as declarações do governo Bolsonaro aqui expostas podem afetar os estudantes na forma de um desrespeito, é necessário aprofundar as discussões teóricas sobre a esfera da estima social.

A teoria formulada por Honneth procura transitar entre as concepções liberais, que enfatizam o princípio da liberdade individual e dos direitos universais, e as propostas comunitaristas, que afirmam que os indivíduos não podem ser vistos como sujeitos atomísticos, ou seja, desvinculados de um contexto social. Nesse sentido, a dinâmica do reconhecimento, em Honneth, entrelaça a igualdade universal das teorias kantianas e o telos ético das proposições aristotélicas. A busca pela autonomia individual é central na teoria de Honneth, assim como uma concepção abstrata de vida boa, pautada na autorrealização pessoal. Isso significa dizer que o sujeito livre, em Honneth, ou o sujeito

\footnotetext{
${ }^{5}$ Legenda pela qual Bolsonaro foi eleito em 2018.
} 
que conquista sua identidade plena, é o indivíduo autônomo e autorrealizado. Sua teoria não se pauta apenas pelo princípio da autonomia ou apenas pela autorrealização; a dinâmica do reconhecimento envolve, ao mesmo tempo, três princípios: cuidado afetivo, igualdade jurídica e realização, respectivamente correspondentes às esferas do amor, direito e estima social (HONNETH, 2003, p. 143). As relações bem-sucedidas de reconhecimento são aquelas que permitem a formação plena da identidade individual, que acontece com o desenvolvimento da autoconfiança (esfera do amor), do autorrespeito (esfera do direito) e da autoestima (esfera da estima social). Portanto, enquanto a conquista da autonomia se dá com o desenvolvimento da autoconfiança e do autorrespeito, a autorrealização acontece, principalmente, quando os sujeitos podem estimar suas próprias habilidades e capacidades; e isso só ocorre com a ajuda de um parceiro de interação, ou seja, dentro de uma comunidade de valores. O sujeito só é capaz de estimar a si mesmo quando a comunidade reconhece suas capacidades e habilidades como importantes.

Portanto Honneth concebe o sujeito livre como sujeito autônomo e autorrealizado, entendendo que liberdade não diz respeito, simplesmente, "à ausência de coerção ou influência externa; ela significa ao mesmo tempo a falta de bloqueios internos, de inibições psíquicas e de angústias” (2009a, p. 273). O sujeito não é livre apenas com a garantia de direitos universais para preservação da autonomia no sentido de tomar decisões livres de coerção externa; ele precisa ter asseguradas as condições de autorrealização e estas, por sua vez, são adquiridas socialmente. Nas afirmações de Honneth (2009a, p. 173):

[...] sem a suposição de uma certa medida de autoconfiança, de autonomia juridicamente preservada e de segurança sobre o valor das próprias capacidades não é imaginável um êxito na autorrealização, se por isso deve ser entendido um processo de realização espontânea de metas da vida autonomamente eleitas.

Dessa forma, quando afirmamos que as declarações do governo Bolsonaro podem ser configuradas como um desrespeito na esfera da estima social, estamos dizendo que esse discurso fere o princípio da autorrealização, pois ameaça o incentivo mútuo de uma comunidade de pessoas fundada na solidariedade, que visa garantir aos sujeitos a segurança sobre o valor das próprias capacidades. 
Se considerarmos que uma concepção individual de felicidade de um estudante universitário pode estar associada à sua realização profissional, ao exercício de determinada profissão, e que o alcance desse objetivo pode passar por uma relação com a universidade, então o desprestígio dessa escolha de vida fere um instrumento essencial para a autorrealização. Portanto, uma narrativa política como a do governo Bolsonaro assume para a comunidade universitária a forma de um desrespeito, pois abre a possibilidade de retirada de um assentimento social das capacidades e realizações individuais dos sujeitos componentes dessa população universitária.

A depreciação de algumas formas de vida, segundo Honneth (2009a, p. 217-218):

[...] tira dos sujeitos atingidos toda a possibilidade de atribuir um valor social às suas próprias capacidades. A degradação valorativa de determinados padrões de autorrealização tem para seus portadores a consequência de eles não poderem se referir à condução de sua vida como a algo a que caberia um significado positivo no interior de uma coletividade; por isso, para o indivíduo, vai de par com a experiência de uma tal desvalorização social, de maneira típica, uma perda de autoestima pessoal, ou seja, uma perda de possibilidade de se entender a si próprio como um ser estimado por suas propriedades e capacidades características.

A fim de compreender melhor as consequências individuais acarretadas pela experiência do desrespeito, Honneth (2009a) recorre a metáforas comumente utilizadas em estudos e pesquisas. Experiências de maus tratos físicos, como tortura e violação, são definidas como "morte psíquica"; privação de direitos e exclusão, descritas como "morte social"; e a degradação cultural de uma forma de vida, como "vexação". A utilização das metáforas mostra que "compete às diversas formas de desrespeito pela integridade psíquica do ser humano o mesmo papel negativo que as enfermidades orgânicas assumem" para o corpo (HONNETH, 2009a, p. 219).

Formas de rebaixamento, de reconhecimento recusado, segundo Honneth (2009a, p. 213):

[...] designam um comportamento que não representa uma injustiça só porque ele estorva os sujeitos em sua liberdade de ação ou lhes inflige danos; pelo contrário, visa-se aquele aspecto de um comportamento lesivo pelo qual as pessoas são feridas numa compreensão positiva de si mesmas, que elas adquiriram de maneira intersubjetiva. 
O desrespeito vivenciado pela denegação da estima social afeta, portanto, a saúde psíquica do indivíduo. A interferência nessas formas de autorrelação consiste no "elo psíquico" entre a experiência do desrespeito e o movimento social. São os sentimentos de vergonha, ira, vexação ou desprezo que são capazes de conduzir o sofrimento à ação ativa, pois essas reações emotivas podem ser diminuídas na medida em que o sujeito encontra uma possibilidade de ação. "O engajamento nas ações políticas possui para os envolvidos também a função direta de arrancá-los da situação paralisante do rebaixamento passivamente tolerado e de lhes proporcionar, por conseguinte, uma autorrelação nova e positiva" (HONNETH, 2009a, p. 259).

O sofrimento individual é uma espécie de sintoma do sentimento de desrespeito. Esse é o "elo psíquico" (2009a, p. 220) que faz com que o sujeito passe do sofrimento para a luta, pois abre a possibilidade para que a pessoa tenha uma compreensão cognitiva da injustiça sofrida, motivando a resistência política (2009a, p. 224). Essa conexão é feita com a ajuda da psicanálise.

Em Una patología social de la razón, Honneth explica o potencial emancipatório do sofrimento moral com uma referência à condição para a psicanálise: o indivíduo que sofre tem o desejo de se libertar desse sofrimento (HONNETH, 2009b, p. 49). No artigo, Honneth traça a história do pensamento na Teoria Crítica a partir da reflexão sobre o diagnóstico das patologias sociais, apontando que os autores dessa tradição teórica têm em comum a visão de que o capitalismo é uma forma de organização social que bloqueia o uso da racionalidade. Outro elemento comum tomado como base para o pensamento dos autores da Teoria Crítica é a utilização de conceitos da psicanálise. Para Honneth, a mesma importância que Hegel, Marx, Weber e Lukács têm para o conteúdo central da Teoria Crítica tem também a psicanálise de Freud, pois “os autores tiram dele a ideia de que as patologias sociais devem sempre se expressar no sofrimento que mantém vivo o interesse pelo poder emancipatório da razão" (HONNETH, 2009b, p. 45).

Segundo Honneth, de Horkheimer a Habermas, a Teoria Crítica se orienta pela ideia freudiana de vincular o sofrimento individual às patologias sociais, o que conduz à tese antropológica de que os sujeitos "não podem se comportar indiferentemente diante de uma restrição de suas faculdades racionais" (2009b, p. 48). Portanto um primeiro importante caminho é a constatação que os indivíduos não reagem com neutralidade à 
injustiça. Um segundo passo, também influenciado pelos estudos de Freud, é a passagem para a práxis, ancorada, conforme já mencionamos, na condição para o início do tratamento psicanalítico, conforme apontado por Honneth (2009b, p. 49-50, tradução nossa):

[...] na Teoria Crítica, pressupõe-se que esse sofrimento experimentado subjetiva ou objetivamente atribuível leva os membros da sociedade ao mesmo desejo de cura, de libertação dos males sociais, que o analista deve assumir em seus pacientes; e tanto em um caso como no outro, o interesse pela própria cura estará documentado na disposição de reativar, apesar das resistências, justamente as capacidades racionais que foram deformadas pela patologia individual ou social. Todos os autores que fazem parte do cerne da Teoria Crítica contam com o interesse latente de seus destinatários em explicações sensatas, em interpretações racionais, pois o desejo de se emancipar do sofrimento só pode ser satisfeito com a recuperação de uma racionalidade intacta. Ora, é esse pressuposto arriscado que permite estabelecer um vínculo entre teoria e práxis diferente daquele que era dado nas tradições marxistas: os defensores da teoria crítica não compartilham com seus destinatários um espaço de objetivos comuns ou projetos políticos, mas um espaço de razões potencialmente comuns que mantém aberto o presente patológico à possibilidade de uma transformação por meio de compreensão racional.

O sofrimento individual é o elemento que guarda o potencial para a práxis política, motivando os sujeitos à luta. No entanto, o potencial de surgimento de uma resistência política depende de outras condições, como o ambiente político e cultural no qual o sujeito está inserido. "Somente quando o meio de articulação de um movimento social está disponível é que a experiência de desrespeito pode tornar-se uma fonte de motivação para ações de resistência política” (HONNETH, 2009a, p. 224).

Entendemos que esse cenário de oportunidades políticas estava presente nas manifestações de maio de 2019 no Brasil. O estopim para os protestos foi o contingenciamento dos recursos destinados às universidades públicas federais. A medida, que sucedeu a uma série de declarações (algumas já citadas aqui) voltadas à comunidade acadêmica, foi inicialmente apresentada como uma penalidade imposta às instituições que estariam promovendo "balbúrdia" em seus campi, conforme declaração do ministro Weintraub ao jornal O Estado de S. Paulo, publicada em 30 de abril. Em decorrência do que o ministro da Educação chamou de bagunça, "sem-terra dentro do campus, gente pelada dentro do campus", a Universidade de Brasília (UnB), a Universidade Federal 
Fluminense (UFF) e a Universidade da Bahia (UFBA) teriam um corte de $30 \%$ em suas dotações orçamentárias anuais (AGOSTINI, 2019).

Após a repercussão negativa das declarações, e com a iminente possibilidade de reversão da decisão juridicamente, o Ministério da Educação (MEC) anunciou um contingenciamento de $30 \%$ estendido a todas as universidades federais (SALDAÑA, 2019). Houve também, em 8 de maio, o congelamento, pela Coordenação de Aperfeiçoamento de Pessoal de Nível Superior (Capes), de mais de 4 mil bolsas de mestrado e doutorado utilizadas para financiamento de pesquisas (CAPES MANTÉM, 2019). ${ }^{6}$ Em 15 de maio, milhares de pessoas foram às ruas em forma de protesto. Em 30 de maio, os atos se repetiram.

Para Honneth (2009a, p. 258), o surgimento de movimentos sociais "depende da existência de uma semântica coletiva que permite interpretar as experiências de desapontamento pessoal como algo que afeta não só o eu individual, mas também um círculo de muitos outros sujeitos". Essa "ponte semântica" é encontrada em doutrinas ou ideias morais, que, além de preencherem as expectativas frustradas pela experiência do desrespeito, revelam "as causas sociais responsáveis por esse sentimento de lesão" (HONNETH, 2009a, p. 258).

O discurso e as medidas adotadas pelo governo fortaleceram o elo semântico entre os indivíduos rebaixados e a ação de resistência. A insurgência universalizada do governo contra a educação abarcou diferentes grupos e indivíduos, tornando mais abrangente a rede de solidariedade que possibilita a integração social em torno de atos de protesto.

Não queremos ocultar, dos protestos de maio, a dimensão de uma luta políticopartidária. As bandeiras de partidos políticos estavam presentes nas manifestações de rua, ocupando o espaço de oposição ao governo Bolsonaro. Da mesma forma, não subestimamos o papel que o anúncio de corte de verbas teve na mobilização popular. Mas o que buscamos demonstrar neste artigo é o potencial das experiências morais dos sujeitos para impulsionar ou ampliar uma ação coletiva.

Percebemos, na existência de uma oposição política engajada em ações de mobilização e na redução do repasse de recursos, elementos fortalecedores da conexão

\footnotetext{
${ }^{6}$ A medida não atingiu as bolsas que estavam sendo pagas, somente as que estavam em processo de transição.
} 
entre o sentimento individual de desrespeito e os atos coletivos de protesto. Convém destacar que o objetivo deste estudo não é advogar pela defesa exclusiva da teoria do reconhecimento para explicar os conflitos contemporâneos, mas mostrar que neste caso específico dos protestos de maio existe uma ligação entre a origem das manifestações e o sentimento de injustiça perante um movimento de ameaça ao reconhecimento. Por um lado, buscamos fundamentar o que definimos como um movimento de desprezo pela universidade, que ameaça as expectativas de reconhecimento da comunidade acadêmica. Por outro lado, queremos investigar nos manifestantes o sofrimento motivado pela frustração de suas expectativas de reconhecimento.

Para isso, identificamos na linguagem das manifestações a expressão de pretensões individuais de reconhecimento e respeito. Após o levantamento das imagens dos movimentos de 15 e 30 de maio, feito principalmente a partir das divulgações da União Nacional dos Estudante (UNE) ${ }^{7}$, verificamos uma busca por demonstrar o valor social da universidade, da pesquisa e do estudante. Vejamos a seguir alguns exemplos:

Durante os atos, estudantes da área da saúde de várias universidades realizaram atendimento gratuito à população, enquanto outros universitários montaram stands para divulgar e explicar resultados de pesquisas. Muitos manifestantes usaram as ruas para demonstrar o trabalho desenvolvido dentro das universidades, conforme indicam os seguintes enunciados: "Nossa balbúrdia salva vidas", "A minha balbúrdia é ciência", "Você sabe para que serve a universidade? Converse comigo!”, "UFSCar cria detectores de Alzheimer", "Obrigada aos drogados pesquisadores da UFF por descobrirem moléculas capazes de combater a leucemia” (UNIÃO NACIONAL, 2019).

Nesses exemplos, vemos uma reafirmação da importância da universidade para a sociedade, associando a pesquisa científica a um trabalho social que possui valor para a comunidade.

Também houve as manifestações dos estudantes da área de humanas: "Lute pela universidade como a Filosofia luta pelo pensamento livre", "Sociedade sem Sociologia é o sonho da tirania" (UNIÃO NACIONAL, 2019). Nessas frases, vemos uma reação direta

\footnotetext{
7 Todas as citações expostas nesta seção do artigo foram retiradas de postagens do perfil da UNE no Instagram, feitas entre os dias 15 e 30 de maio de 2019 (UNIÃO NACIONAL, 2019).
} 
às declarações do governo sobre a possibilidade de redução de verbas federais destinadas aos cursos de humanas. A reação se faz pela afirmação da importância social dessas disciplinas.

É interessante observar que, dentro dos atos coletivos, cada pessoa podia ser sua própria manifestação. Existiam os slogans máximos trazidos em faixas, como "Contra o corte de verbas" ou "Em defesa da educação", mas muitas pessoas levaram seus próprios cartazes, pintados à mão e à base de um certo improviso. Neles foi possível encontrar palavras como "respeito" e "sofrimento", e muitas frases que indicavam uma reafirmação identitária (estudante, pesquisador), sugerindo um desejo de recuperar uma autoestima violada.

Transcrevemos alguns dizeres estampados nos cartazes de manifestantes: "Queremos respeito, queremos educação", "Vamos mostrar que somos gente", "Em defesa da vida, da universidade e da dignidade humana", "Lute como uma estudante", "Lute como uma bolsista", "Lute como uma cientista", "A vida inteira sonhei em estar aqui, não tirem a universidade de mim", "Tanto sofrimento que não cabe num cartaz" (UNIÃO NACIONAL, 2019).

As declarações demonstram o significado que a universidade tem para os manifestantes; mais do que um meio para seus projetos pessoais, podemos perceber que ela aparece como um sinônimo de vida, de dignidade humana, de ser gente, ou seja, de existir como um sujeito social. Percebemos a universidade como uma parte essencial da vida dos sujeitos, tanto que observamos uma autodefinição pela condição de ser estudante, ser bolsista e ser cientista. É interessante observar que o apelo "não tirem a universidade de mim" mostra uma associação da universidade à vida, à concepção do indivíduo sobre si mesmo, o que vai muito além de um meio para se atingir o que deseja, caso contrário a frase dita poderia ter sido: "não me tirem da universidade", mas a forma como foi exposta mostra a universidade como parte de si mesmo, e, portanto, a defesa da universidade é uma defesa de si mesmo. Dessa forma, podemos ver que as ofensas dirigidas à universidade refletem na relação que o sujeito tem consigo próprio.

Com essas exposições buscamos, em um primeiro momento, mostrar que na linguagem das manifestações é possível identificar uma defesa da importância e do valor da universidade, o que nos permite descrever os atos de protesto como uma reação às 
ofensas que ameaçam o reconhecimento intersubjetivo na esfera da estima social. Em um segundo momento, trouxemos exemplos de como essas agressões impactam na visão que os universitários têm de si mesmos, mostrando que a injustiça social na forma de um desrespeito pelo não reconhecimento pode causar um sofrimento individual que torna os sujeitos dispostos a se engajarem em manifestações sociais.

Com isso, concluímos esta seção que se propôs a refletir sobre a estrutura moral das manifestações de maio, abordando a motivação dos protestos na chave de uma luta por reconhecimento, resultante da ruptura do respeito intersubjetivo por um movimento de depreciação social da comunidade acadêmica.

\section{$3 \mathrm{O}$ reconhecimento na esfera do direito}

Até aqui, discorremos sobre uma ação de desrespeito gerada por um movimento do governo de desprezo pela universidade, enfraquecendo as condições garantidoras de uma relação simétrica de estima social. A partir de agora, buscaremos mostrar que essa ameaça à consolidação do reconhecimento recíproco a partir da solidariedade pode se estender à esfera do direito, deixando transparecer que a desvalorização social da universidade pode guardar a intenção de interferência em um direito social: a educação superior.

Quando atribuímos à ação de desvalorização da comunidade acadêmica a qualidade de um "movimento", pensamos não somente no sentido que a palavra assume para designar manifestações sociais, mas também em sua acepção de "ação de mover", sugerindo, dessa forma, a ideia de um processo de desvalorização, que pode ter sua dimensão de desrespeito ampliada, saindo da esfera da solidariedade e atingindo a das relações jurídicas.

Para refletir sobre essa questão, fazemos um breve resgate de uma parte da história do movimento estudantil no Brasil. Em maio 1979, 10 mil estudantes universitários se reuniram em Salvador (BA) para o $30^{\circ}$ Congresso da UNE, denominado Congresso de Reconstrução da entidade (ROMAGNOLI, 1979). A UNE 
havia sido legalmente extinta pela lei Suplicy de Lacerda ${ }^{8}$ em 1964, após o golpe militar. O evento de 1979 mostrava que a UNE, embora não existisse legalmente, possuía representatividade no meio estudantil e também uma dose de reconhecimento social, já que o Congresso de Reconstrução contou com o apoio de diversas entidades sociais e instituições. A UNE só voltaria a contar com o reconhecimento legal em 1985, com a lei 7.395, aprovada pelo Congresso Nacional. A entidade havia sido criada em 1937, sendo oficialmente reconhecida em 1942, por meio do decreto 4.105.

Nessa breve história da UNE, podemos observar dois movimentos distintos: um de reconhecimento legal e o outro de "desreconhecimento", quando a entidade foi proscrita durante o regime de exceção. Esses fatos abrem a possibilidade de pensar sobre um processo de subtração de um reconhecimento, quando o reconhecimento, seja ele social ou legal, já existe e o que se observa é um movimento de retirada.

Com esse exemplo, buscamos fundamentar a ideia de que está em curso um movimento de "desreconhecimento" que atinge o valor social da universidade e ameaça direitos estabelecidos. Assim, o movimento de desvalorização da universidade tem início na esfera da estima social e guarda a possibilidade de extensão para o âmbito do direito. Enquanto na esfera da estima social o dimensionamento do que está sendo ameaçado é uma reflexão mais subjetiva, na esfera do direito, o que está em risco fica mais claro e objetivado. A iniciativa do governo de efetuar cortes nos repasses às universidades federais pode ser vista como uma tentativa prática de restrição de uma norma vigente, já que a justificativa de um contingenciamento linear veio após declarações do ministro Weintraub de represália a determinadas instituições de ensino. Entendemos que a redução orçamentária e a diminuição do financiamento à pesquisa por meio do corte de bolsas de estudo excedem a categoria administrativa e econômica quando associadas a um discurso ideologizado antipluralista.

Vemos a educação pública universitária no Brasil, um país com grande desigualdade de renda, ${ }^{9}$ como uma política de justiça social. Se considerarmos a distinção dos três direitos feita por T. H. Marshall (1967), direitos civis de liberdade, direitos

\footnotetext{
${ }^{8}$ A lei no 4.464, de 9 de novembro de 1964, ficou conhecida como Lei Suplicy de Lacerda em referência ao então ministro da Educação, Flávio Suplicy de Lacerda, mentor da norma que extinguiu a UNE como órgão de representação dos universitários e impôs uma série de restrições aos diretórios acadêmicos.

${ }^{9}$ Dados do IBGE, divulgados em 2019, mostram o aumento da desigualdade no Brasil (NERY, 2019).
} 
políticos de participação e direitos sociais de bem-estar, a universidade pública, bem como as bolsas de estudo, além de um incentivo à pesquisa científica, visam garantir justiça social, no sentido de reparo das desigualdades de acesso à educação. $O$ contingenciamento de recursos e o recolhimento de bolsas, ainda que pudessem se configurar como um ato administrativo ou uma medida econômica, não excluem a possibilidade de serem vistos como uma tentativa de subtração de direitos.

Em que pese o "descontingenciamento" orçamentário anunciado em outubro de 2019 pelo Ministério da Educação (MEC LIBERA, 2019), bem como a retomada de parte das bolsas que haviam sido represadas, o que podemos verificar é um momento em que a evolução dos direitos sofre uma ameaça de retrocesso.

\section{Considerações finais}

Este trabalho iniciou-se com o propósito de analisar as manifestações de maio de 2019 no Brasil a partir dos fundamentos da teoria do reconhecimento de Honneth. Com isso, buscamos reconstruir a lógica desses protestos, com origem em um movimento de desvalorização da universidade, expressado na retórica do governo Bolsonaro, cujas ofensas lançadas afetam o meio universitário na forma de um desrespeito.

Fizemos um resgate das notícias veiculadas em três importantes jornais impressos de circulação diária e abrangência nacional, a fim de contextualizar os atos de protesto, registrando que a população ligada à universidade foi um dos principais sujeitos das manifestações. Assim, focamos nossa análise nos estudantes universitários e buscamos investigar se eles se sentiram afetados pela retórica de depreciação da universidade, proferida pelo governo Bolsonaro. Mostramos como os indivíduos, quando afetados por um sofrimento, se tornam dispostos ao engajamento em uma práxis política, a fim de superarem a situação de rebaixamento vivida. Também indicamos que o cenário político, montado com discursos do governo e com o anúncio de corte de verbas, se tornou propício à criação de uma rede de solidariedade que viabilizasse a emergência de um movimento social. Partimos, então, para o levantamento de fotografias que registrassem a linguagem dos estudantes universitários que participaram dos atos. Buscamos imagens divulgadas no Instagram da UNE e identificamos, nos cartazes dos manifestantes, a expressão de um 
sofrimento individual e de uma busca por reafirmar o valor social de ser estudante e pesquisador e a importância da universidade para a sociedade.

Concluímos que nos atos de maio de 2019 em defesa da educação é possível identificar uma motivação moral de uma luta por reconhecimento na esfera da estima social, pois a universidade pode ser identificada como parte essencial da concepção que os manifestantes têm de si mesmos como sujeitos sociais e como indivíduos autorrealizados. A experiência de desprezo pelo valor social da universidade está relacionada, na forma de espelho, a um sentimento individual de diminuição da autoestima, que se expressa socialmente por uma disposição pessoal para o engajamento em ações de protestos.

No decorrer dessa análise, vimos que esse movimento que atinge a esfera do reconhecimento pela estima social guarda a possibilidade de ampliação para as relações jurídicas, sendo possível indicar que está em curso uma ação de "desreconhecimento" do valor social e jurídico da universidade. O movimento de depreciação do valor social ocorre junto a uma tentativa de redução dos recursos destinados às universidades públicas, indicando que a ação discursiva pode servir como uma tentativa de legitimar uma intervenção na esfera do direito. Entendemos a educação universitária pública, assim como o financiamento público às pesquisas acadêmicas, como um direito social; e a tentativa de corte de recursos, respaldada por um discurso "rivalista", vai além de uma mera medida econômica ou administrativa, podendo ser associada a um movimento que vai na contramão da inclusão social e do respeito à pluralidade.

\section{Referências}

AGOSTINI, Renata. MEC cortará verba de universidade por 'balbúrdia' e já enquadra UnB, UFF e UFBA. O Estado de S. Paulo, 30 abr. 2019, Disponível em: https:/educacao.estadao.com.br/noticias/geral,mec-cortara-verba-de-universidade-porbalburdia-e-ja-mira-unb-uff-e-ufba,70002809579. Acesso em: 16 dez. 2019.

ATOS mobilizam 170 cidades contra arrocho na educação. Folha de S. Paulo, São Paulo, ano 99, n. 32.915, 16 mai. 2019. Cotidiano, p. A1.

BATISTA, Henrique Gomes; ORTE, Paola. Bolsonaro chama manifestantes pela Educação de 'idiotas úteis'. Valor, O Globo, 15 mai. 2019. Disponível em: https://www.valor.com.br/politica/6256929/bolsonaro-chama-manifestantes-pelaeducacao-de-\%3Fidiotas-uteis\%3F. Acesso em: 16 dez. 2019. 
BOLSONARO DIZ que jovem brasileiro tem 'tara' por formação superior. Exame. 29 ago. 2018. Disponível em: https://exame.abril.com.br/brasil/bolsonaro-diz-que-jovembrasileiro-tem-tara-por-formacao-superior/. Acesso em: $16 \mathrm{dez} .2019$.

BOLSONARO, Jair M. Uma das metas para tirarmos o Brasil das piores posições nos rankings de educação do mundo é combater o lixo marxista que se instalou nas instituições de ensino. Junto com o Ministro de Educação e outros envolvidos vamos evoluir em formar cidadãos e não mais militantes políticos. 31 dez. 2018. Twitter: @jairbolsonaro. Disponível em: https://twitter.com/jairbolsonaro/status/ 1079686972673806336. Acesso em: 16 dez. 2019.

CAPES MANTÉM o pagamento de todas as bolsas em vigor. CCS/CAPES, 9 mai. 2019. Disponível em: https://www.capes.gov.br/36-noticias/9477-capes-mantem-opagamento-de-todas-as-bolsas-em-vigor. Acesso em: 16 dez. 2019.

GOVERNO enfrenta protestos de rua e pressão no Congresso. O Estado de S. Paulo, São Paulo, ano 140, n. 45.866, 16 mai. 2019. Política, p. A1.

GUIMARÃES, Hellen. É \#FAKE que universidades não comprovaram destino de 30\% dos recursos. Valor, O Globo, 9 mai. 2019. Disponível em: https://www.valor.com.br/fatooufake/6247713/e-fake-que-universidades-nao-comprova ram-destino-de-30-dos-recursos. Acesso em: 16 dez. 2019.

HONNETH, Axel. Luta por reconhecimento: a gramática moral dos conflitos sociais. São Paulo: Editora 34, 2009a [1992].

HONNETH, Axel. Una patología social de la razón. In: Patologías de la razón: historia y actualidad de la teoría crítica. Buenos Aires: Katz Editores Charlone, 2009b, p. 27-51.

HONNETH, Axel. Redistribution as recognition: a response to Nancy Fraser; The point of recognition: A rejoinder to the rejoinder. In: FRASER, Nancy; HONNETH, Axel. Redistribution or recognition? A political-philosophical exchange. London; New York: Verso, 2003, p. 110-197 e p. 237-267.

HOSTILIDADE como método. O Estado de S. Paulo, São Paulo, ano 140, n. 45.867, 17 mai. 2019. Notas e informações, p. A3.

IDIOTA inútil. Folha de S. Paulo, São Paulo, ano 99, n. 32.916, 17 mai. 2019. Opinião, p. A2.

LINDNER, Julia. Bolsonaro: 'Queremos uma garotada que comece a não se interessar por política'. O Estado de S. Paulo, 9 abr. 2019, Disponível em: https:/educacao.estadao.com.br/noticias/geral,bolsonaro-queremos-uma-garotada-quecomece-a-nao-se-interessar-por-politica,70002785320. Acesso em: 16 dez. 2019.

LOPES, Nathan. MEC estuda reduzir investimento em faculdades de humanas, diz Bolsonaro. Uol, 26 abr. 2019. Disponível em: https://educacao.uol. com.br/noticias/2019/04/26/bolsonaro-faculdades-humanas-investimento.htm. Acesso em: 16 dez. 2019.

MAIS de 200 cidades têm atos contra cortes na educação. O Globo, Rio de Janeiro, ano XCIV, n. 31.328, 16 mai. 2019. Sociedade, p. 1. 
MANIFESTANTES vão às ruas contra cortes da educação em ao menos 170 cidades. Folha de S. Paulo, São Paulo, ano 99, n. 32.915, 16 mai. 2019. Cotidiano, p. B1.

MARSHALL, Thomas Humphrey. Cidadania, classe social e status. Rio de Janeiro: Zahar Editores, 1967 [1950].

MEC LIBERA $100 \%$ do orçamento de universidades e institutos federais. Ministério da Educação, 18 out. 2019. Disponível em: http://portal.mec.gov.br/ component/content/article?id=81431. Acesso em: 3 dez. 2019.

NÃO SE GOVERNA por meio de confrontos. O Globo, Rio de Janeiro, ano XCIV, n. 31.329, 17 mai. 2019. Opinião do Globo, p. 2.

NERY, Carmen. Extrema pobreza atinge 13,5 milhões de pessoas e chega ao maior nível em 7 anos. Agência IBGE Notícias, Editoria Estatísticas Sociais. 6 nov. 2019. Disponível em: https://agenciadenoticias.ibge.gov.br/agencia-noticias/2012-agencia-denoticias/noticias/25882-extrema-pobreza-atinge-13-5-milhoes-de-pessoas-e-chega-aomaior-nivel-em-7-anos. Acesso em: 16 dez. 2019.

NOBRE, Marcos. A teoria crítica. Rio de Janeiro: Zahar, 2011 [2004], Edição Kindle.

PELA EDUCAÇÃO. Multidão vai às ruas contra cortes no MEC. O Globo, Rio de Janeiro, ano XCIV, n. 31.328, 16 mai. 2019. Sociedade, p. 24.

PROTESTOS de rua elevam desgaste do governo. O Estado de S. Paulo, São Paulo, ano 140, n. 45.866, 16 mai. 2019. Política, p. A4.

SALDAÑA, Paulo. MEC estende corte de 30\% de verbas a todas universidades federais. Folha de S. Paulo, 30 abr. 2019. Disponível em: https://www1.folha.uol. com.br/educacao/2019/04/mec-estende-corte-de-30-de-verbas-a-todas-universidadesfederais.shtml. Acesso: 16 dez. 2019.

TRUFFI, Renan; RIBEIRO, Marcelo. Aliados de Bolsonaro criticam manifestantes: 'Fumadores de maconha'. Valor, O Globo, 15 mai. 2019. Disponível em https://www.valor.com.br/politica/6257529/aliados-de-bolsonaro-criticam-manifestante s-fumadores-de-maconha. Acesso em: 16 dez. 2019.

UNIÃO NACIONAL dos Estudantes (UNE). Cartazes de manifestantes. Instagram: uneoficial. Disponível em: https://www.instagram.com/uneoficial/. Acesso em: 21 jul. 2019.

WEINTRAUB, Abraham. Live com nosso presidente @jairbolsonaro (parte2). 10 mai. 2019. Twitter: @AbrahamWeint. Disponível em: https://twitter.com/ AbrahamWeint/status/1126839802467356673?s=20. Acesso em: 16 dez. 2019.

Recebido em: 30/08/20.

Aceito em: 31/10/20. 